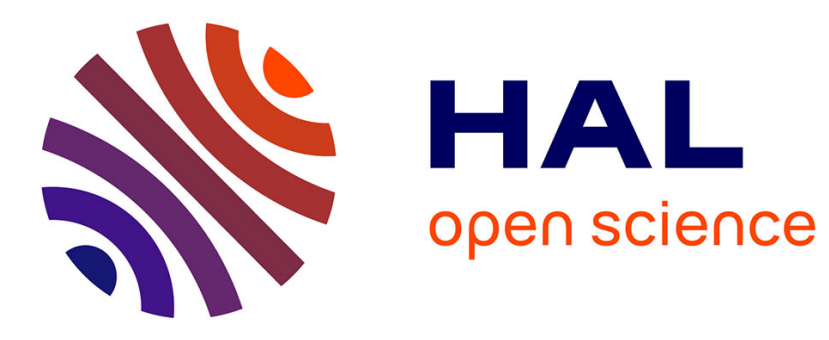

\title{
Compositional Changes at the Early Stages of Nanoparticles Growth in Glasses
}

\author{
Wilfried Blanc, Isabelle Martin, Hugues Francois-Saint-Cyr, Xavier Bidault, \\ Stéphane Chaussedent, Chrystel Hombourger, Sabrina Lacomme, Philippe Le \\ Coustumer, Daniel R Neuville, David Larson, et al.
}

\section{To cite this version:}

Wilfried Blanc, Isabelle Martin, Hugues Francois-Saint-Cyr, Xavier Bidault, Stéphane Chaussedent, et al.. Compositional Changes at the Early Stages of Nanoparticles Growth in Glasses. Journal of Physical Chemistry C, 2019, 123 (47), pp.29008-29014. 10.1021/acs.jpcc.9b08577 . hal-02500050

\section{HAL Id: hal-02500050 https://hal.science/hal-02500050}

Submitted on 5 Mar 2020

HAL is a multi-disciplinary open access archive for the deposit and dissemination of scientific research documents, whether they are published or not. The documents may come from teaching and research institutions in France or abroad, or from public or private research centers.
L'archive ouverte pluridisciplinaire $\mathbf{H A L}$, est destinée au dépôt et à la diffusion de documents scientifiques de niveau recherche, publiés ou non, émanant des établissements d'enseignement et de recherche français ou étrangers, des laboratoires publics ou privés. 


\title{
Compositional Changes at the Early Stages of Nanoparticles Growth in Glasses
}

\author{
Wilfried Blanc, ${ }^{*}+\odot$ Isabelle Martin,,$^{\ddagger}$ Hugues Francois-Saint-Cyr, ${ }^{\ddagger}$ Xavier Bidault, ${ }^{\S}$ \\ Stéphane Chaussedent, ${ }^{\S}$ Chrystel Hombourger," Sabrina Lacomme, ${ }^{\perp}$ Philippe Le Coustumer, ${ }^{\perp, \#}$ \\ Daniel R. Neuville, ${ }^{\bigcirc}$ David J. Larson, ${ }^{\ddagger}$ Ty J. Prosa, ${ }^{\ddagger}$ and Christelle Guillermier ${ }^{\mathbb{T},} \nabla$ \\ 'Institut de Physique de Nice (INPHYNI), Université Côte d'Azur, CNRS UMR7010, Parc Valrose, 06108 Nice, France \\ ${ }^{\ddagger}$ CAMECA Instruments Inc., 5470 Nobel Drive, Madison, Wisconsin 53711, United States \\ ${ }^{\S}$ Laboratoire de Photonique d'Angers (LPhiA)-UPRES EA 4464, Université d'Angers, 2 Bd Lavoisier, 49045 Angers Cedex 01, \\ France \\ "CAMECA S.A., 29 Quai des Grésillons, 92230 Gennevilliers, France \\ ${ }^{\perp}$ Bordeaux Imaging Center (UMS3420 CNRS - Université de Bordeaux/US4 INSERM), Bordeaux, France \\ \#Université de Bordeaux, B.18, Allée Geoffroy Saint-Hilaire, CS 50023, 33615 Pessac cédex, France \\ OInstitut de Physique du Globe de Paris, CNRS-Géomatériaux, Sorbonne Paris Cité, 1 rue Jussieu, 75005 Paris, France \\ II Center for NanoImaging, Brigham and Women's Hospital, Harvard Medical School, Cambridge, Massachusetts 02139, United \\ States
}

Supporting Information

ABSTRACT: Doping material with nanoparticles is increasingly used as an effective method for improving their mechanical, optical, and sturdiness properties in many fields. More specifically, effective material development will depend on our ability to control nanoparticles' shape, composition, and size. While crystalline nanophase can be examined easily, characterization of amorphous nanoparticles remains a challenge. Here, we investigate the chemical composition of sub-20-nm oxide nanoparticles grown in rare-earth doped silicate glass through the phase separation mechanism occurring under heat treatment. Using a combination of analytical techniques, we demonstrate that nanoparticle composition and, therefore, the chemical environment of encapsulated

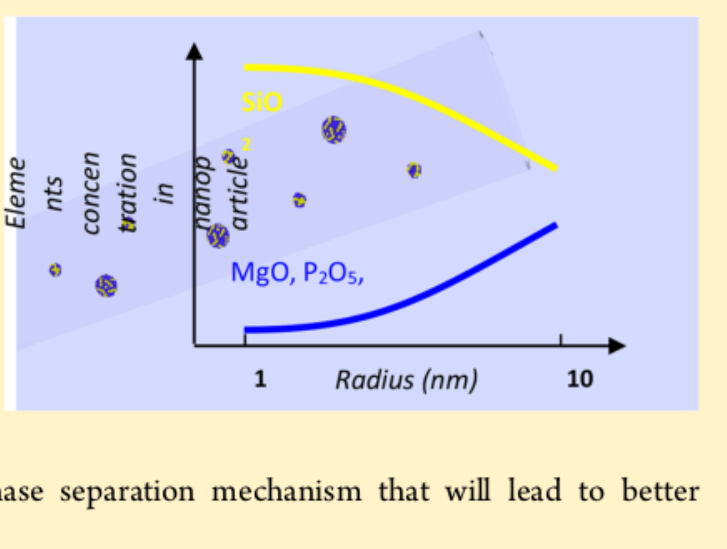
evidence of composition change contributes unique insights on the phase separation mechanism that will lead to better comprehension and will guide development of future materials.

\section{INTRODUCTION}

Nanocomposite glasses are comprised of crystalline or amorphous nanoparticles, embedded in a glassy host. These glasses are known for their broad range of uses, from technological consumer applications (cooktops, dental implants, information storage, etc.), to materials and natural sciences. ${ }^{1-3}$ Crystalline or amorphous nanoparticle-doped glasses usually are obtained by heating homogeneous glass or by cooling melts to initiate nucleation via the phase separation mechanism. However, although extensively studied for the past 60 years, the exact mechanism causing the nanoparticles formation, especially the first nuclei, has remained elusive, due to the lack of characterization techniques for exploring small $(<20 \mathrm{~nm})$ amorphous nanoparticles.

In this article, we focus on glass containing nanoparticles doped with rare-earth ions. Such nanocomposite glasses have become material of prime importance in photonics. ${ }^{4-8}$ These materials are of interest as they can combine (i) mechanical, chemical, and financial advantages of the glassy host matrix with (ii) engineering rare-earth ions spectroscopic properties, by controlling both nanoparticles' composition and structure. A major issue in using composite glasses is material-diminished transparency, an important drawback for optical fibers. Consequently, nanometric-size particles are preferred, as they limit light scattering. ${ }^{9-11}$ More generally, the material's performance depends on the ability to grow and control nanoparticles size, shape and chemical composition. ${ }^{12,13}$ However, due to their small size, their characterization, critical for material optimization, remains a challenge. Rare-earthdoped crystalline nanoparticles characterization requires techniques such as $\mathrm{X}$-ray diffraction (XRD) and electron microscopies (transmission electron microscopy, TEM), ${ }^{14}$ 

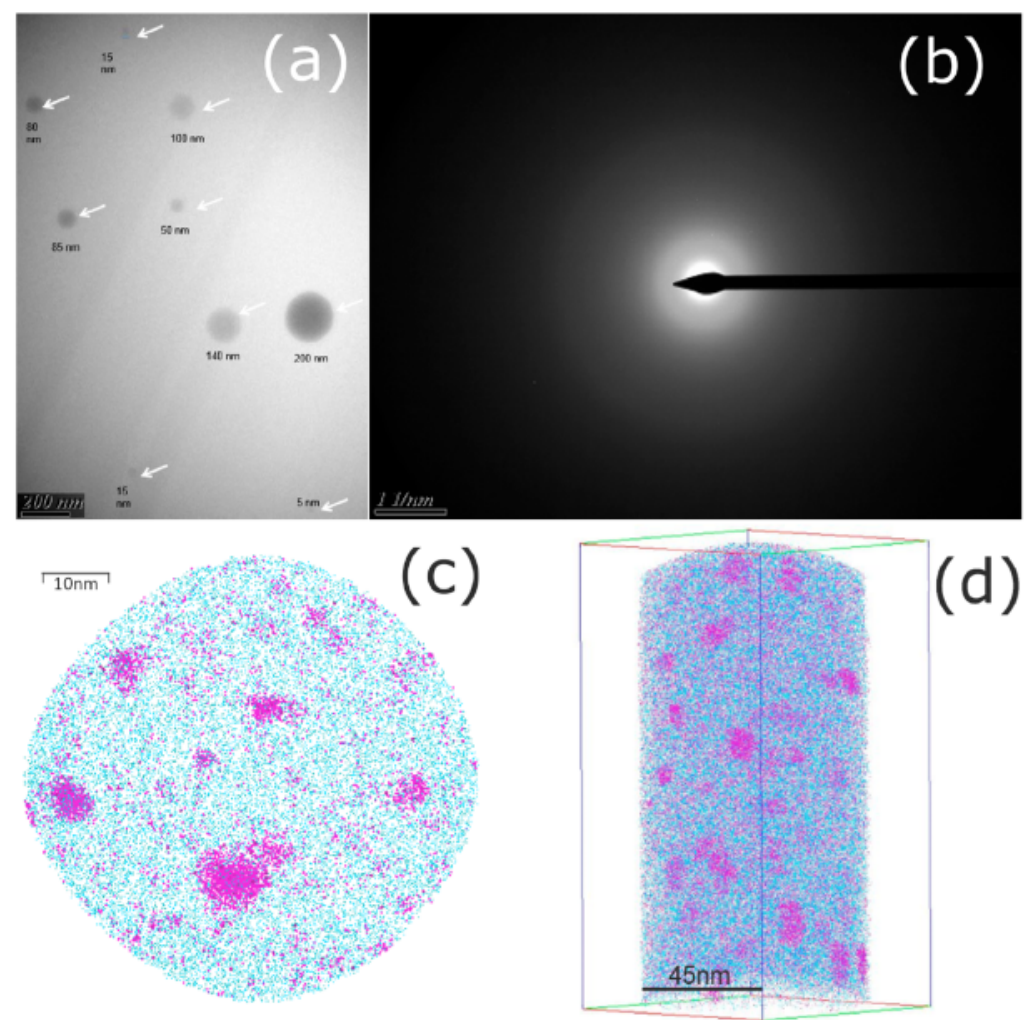

Figure 1. (a) Nanoparticles observed by TEM. They correspond to location close to the central region of the fiber core. Particle size varies between a few nanometers and $200 \mathrm{~nm}$. (b) Diffraction pattern (SAED) on nanoparticles. The particles are amorphous. (c) XY orientation map of 3D distribution. The $\mathrm{Mg}$ is in pink and the $\mathrm{O}$ is in blue. (d) APT reconstruction of $\mathrm{Mg}$-based nanoparticles surrounded by silica matrix.

combined with fluorescence, to successfully determine their crystalline structures and chemical composition. The partition of rare-earth ions inside nanoparticles is usually clearly revealed by a change in the emission spectrum shape. In the crystalline environment, the emission spectrum displays a peak, versus a broad band in the glassy host. ${ }^{15}$

Amorphous phase-separated nanoparticles, on the other hand, are of interest as they offer broader bandwidth gains than do crystalline structures. However, the lack of straightforward characterization techniques for these amorphous structures is a serious impediment to developing such material. Energy dispersive X-ray (EDX) analysis, for example, requires preparing ultrathin layer samples-thinner than the nanoparticles diameters-to be confident about composition assessment. Additionally, specimen preparation producing only small nanoparticles amounts would be statistically detrimental. Since rare-earth fluorescence emission spectra inside and outside amorphous nanoparticles differs very slightly in shape, the spectra interpretation is more complicated than that of crystalline structures.

In this study, we employed $3 \mathrm{D}$ atom probe tomography (APT) to investigate variation in chemical composition and $\mathrm{Er}^{3+}$ partitioning in amorphous nanoparticles grown in silicate glass $\left(\mathrm{SiO}_{2}-\mathrm{GeO}_{2}-\mathrm{MgO}-\mathrm{P}_{2} \mathrm{O}_{5}\right)$ via heat treatments. The specific system studied was the core of an optical fiber drawn from a preform prepared according to the modified chemical vapor deposition (MCVD) process described in the Supporting Information. Previous reporting on large nanoparticles investigated via secondary ion mass spectrometry has shown qualitative concentration variations for $\mathrm{Mg}$ and $\mathrm{P}$ from the matrix to the particle. ${ }^{16}$ However, the technique's high detection limit did not permit gathering $\mathrm{Er}$ information. Here, we provide the first comprehensive experimental data set that describes concentration variations for elements such as $\mathrm{P}$, $\mathrm{Mg}$, and $\mathrm{Er}$ for nanoparticles with radii spanning 1 to $10 \mathrm{~nm}$. To discuss the $\mathrm{Er}^{3+}$ environment in nanoparticles, we apply molecular dynamics simulations, as they have recently demonstrated the ability to reproduce phase-separated nanoparticles in the $\mathrm{SiO}_{2}-\mathrm{MgO}$ system. ${ }^{17}$ This study shows: (1) high "unexpected" density of small nanoparticles $(<10 \mathrm{~nm})$; (2) composition variation with nanoparticle size; (3) $\mathrm{Er}^{3+}$ ions partition within amorphous oxide nanoparticles; and (4) chemical variation of $\mathrm{Er}^{3+}$ ion local environments with nanoparticle size.

\section{RESULTS}

Nanoparticle Composition. Nanoparticles in the fiber core were characterized by two techniques: APT and TEM. Briefly, the APT experiment is based on the pulse-triggered field evaporation process of ions from a needle-shaped specimen tip in an ultrahigh vacuum and cryogenic environment, followed by recording the ions' positions on a delay-line detector. Combining time-of-flight (TOF) spectroscopy and point projection microscopy results in tridimensional reconstruction of evaporated volume as described in the Supporting Information. The TEM image of a fiber core and the APT reconstruction of $\mathrm{Mg}$-based nanoparticles surrounded by silica matrix, are shown in Figure 1, parts a and d, respectively. TEM sample preparation led to observation of nanoparticles within a 4-200 $\mathrm{nm}$ range, with spherical shapes for the largest ones 
(Figure 1a). The top-sliced view of ATP reconstructed volume (Figure 1c) highlights a high density of nanoparticles with a diameter less than $10 \mathrm{~nm}$, something not observed with TEM. The selected area electron diffraction pattern (SAED), Figure $1 \mathrm{~b}$, reveals diffusion rings typical of noncrystalline structures, demonstrating that nanoparticles are amorphous. Therefore, their chemical characterization cannot be derived from X-ray diffraction patterns. Additionally, spatial resolution of X-EDS in nanoprobe mode (typically $\sim 50 \mathrm{~nm}$ ) does not permit elementary analysis of nanoparticles smaller than $10 \mathrm{~nm}$.

One APT strength is its ability to spatially determine chemical information in buried interfaces and particles. This is usually achieved postreconstruction by defining a region of interest (ROI) such as a cube, cylinder, or sphere. Then the volume of the ROI is interrogated based on either the number of ions per counting block or the thickness per slice, over the full ROI in a specific analysis direction. However, as the goal is to quantify chemical content of the nanoparticles as accurately as possible, we applied the proximity histogram, or proxigram (a mathematical approach), ${ }^{18}$ to calculate concentration profiles of distance from iso-concentration surfaces-also called isosurfaces. The isosurfaces are mathematically defined by meshing polygons passing through volume pixels, or voxels, of a specific content (at. \%) or ions-density (ions $/ \mathrm{nm}^{3}$ ).

The proxigram displayed in Figure 2 represents the average concentration of $\mathrm{Mg}, \mathrm{Er}, \mathrm{P}$, and $\mathrm{Ge}$ for particles with radii in a

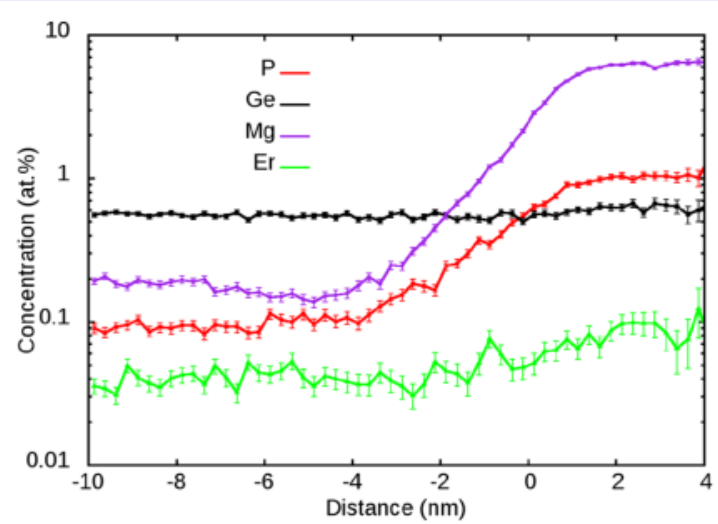

Figure 2. Proximity histogram displaying the evolution of $\mathrm{Mg}, \mathrm{Er}, \mathrm{P}$, and $\mathrm{Ge}$ concentrations from the silica matrix toward the center of the $\mathrm{Mg}$-based dielectric nanoparticles.

5-8 $\mathrm{nm}$ range. Error bars are based on the statistical counting errors method detailed elsewhere, ${ }^{19}$ and they account for the background level under each mass-to-charge $(\mathrm{m} / \mathrm{n})$ peak ratio reached during reconstruction. Similar quantitative results on mass spectra were obtained using either manual data processing or the range-assisted background model, and were implemented directly in IVAS. In atom probe tomography, due to trajectory aberrations induced by the difference in evaporation field between the matrix and the dielectric nanoparticles, we can only provide an estimate of the error on the $3 \mathrm{D}$ reconstruction. A pioneer publication from Sha and Cerezo $^{20}$ has reported a $15 \%$ to $20 \%$ range in error bars for the particle size based on the substantial difference in evaporation field in their system containing $\mathrm{ZrO}$ particles $(\sim 36 \mathrm{~V} / \mathrm{nm})$ in an $\mathrm{Al}$ matrix $(19 \mathrm{~V} / \mathrm{nm})$. Moreover, another contribution from Marquis and Vurpillot ${ }^{21}$ treats precipitates smaller than $10 \mathrm{~nm}$ in radii with differences in evaporation fields of about $10 \%$ between matrix and particles. The resulted reconstruction led to a maximum shift of $1-1.5 \mathrm{~nm}$ in the atom positioning, which represents a $10-15 \%$ change in standard deviation. Our system falls closer to the second case scenario and would provide us with an estimated $10-15 \%$ uncertainty in the measurements presented in this present article. However, the exact uncertainty for our particle sizes measurements is not known and it is not provided.

Compared to the matrix, there is clear nanoparticle enrichment in $\mathrm{Mg}$ and $\mathrm{P}$ of approximately 100 -fold and 10fold respectively, with the $0 \mathrm{~nm}$ distance value corresponding to the interface between matrix and particles for isoconcentration surfaces set at 3 at. $\%$ for $\mathrm{Mg}$. The 3 at. $\%$ was chosen to achieve visualization, but has no effect on quantitation. Most importantly, we observed a clear uptake trend in Er. The mean concentration of Er ions is estimated at $635 \mathrm{ppm} \pm 101 \mathrm{ppm}$ in nanoparticles larger than $150 \mathrm{~nm}^{3}(r>$ $3.3 \mathrm{~nm}$ ) and at $46 \mathrm{ppm} \pm 10 \mathrm{ppm}$ in the total bulk volume. The $\mathrm{Ge}$ trend was not as clearly defined as that for $\mathrm{P}$ and $\mathrm{Mg}$. In some nanoparticles, the $\mathrm{Ge}$ ion concentration appeared similar to that of the matrix (Figure 2) while for other particles it was slightly higher. Although $\mathrm{Mg}, \mathrm{P}$ and $\mathrm{Er}$ ions are clearly partitioned within nanoparticles, the $\mathrm{Si}$ ion concentration is only $20 \%$ lower in the nanoparticle when compared to the matrix. The transition from nanoparticles to matrix appears to occur within less than $5 \mathrm{~nm}$ and is definitely not sharp. We did not observe any obvious core-shell structure although it was reported in the case of alloys. ${ }^{22}$

APT sensitivity at the atomic level enables direct measurement of $\mathrm{Mg}$ and $\mathrm{P}$ contents in nanoparticles for the entire [1$10 \mathrm{~nm}$ ] radii range. Concentration variation for $\mathrm{Mg}$ and $\mathrm{P}$, with nanoparticle size variation (Figure 3 ), is identical for both

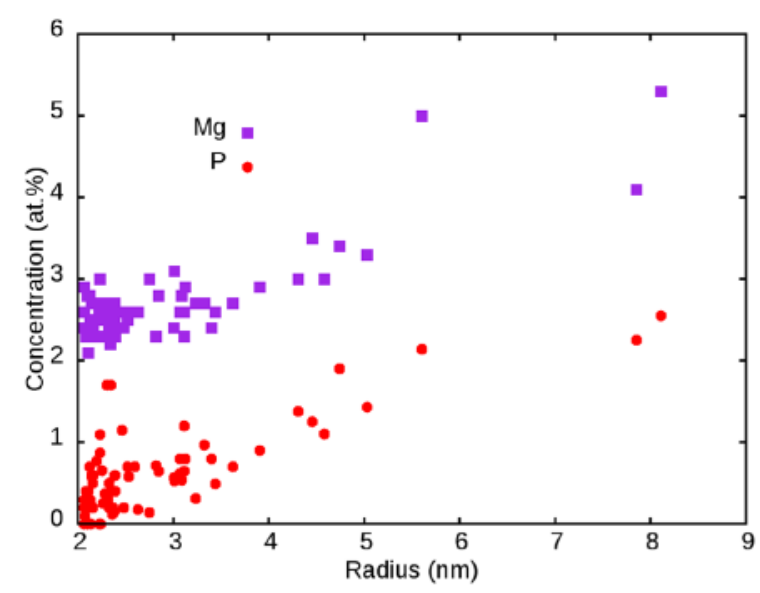

Figure 3. Concentration of $\mathrm{Mg}$ and $\mathrm{P}$ in the nanoparticles vs their radius measured by APT.

elements. The concentration is constant up to a $3.5 \mathrm{~nm}$ radius and then increases in particles with radii larger than $3.5 \mathrm{~nm}$. We also observed that $\mathrm{Si}$ concentration slightly decreases within this nanoparticle size range.

Within the numerous tips analyzed, we found only a limited number of nanoparticles with radii larger than $6 \mathrm{~nm}$. The $\mathrm{Mg}$ and $\mathrm{P}$ concentration in particles with radii larger than $60 \mathrm{~nm}$ were investigated via X-EDS analysis in nanoprobe mode and parallel electron beam. These contents were estimated to be $20-25$ at. $\% \mathrm{Mg}$ and $3.5-5$ at. \% P. These values may be underestimated as the smallest nanoparticles may be dissolved during the TEM sample HF acid cleaning process. APT 


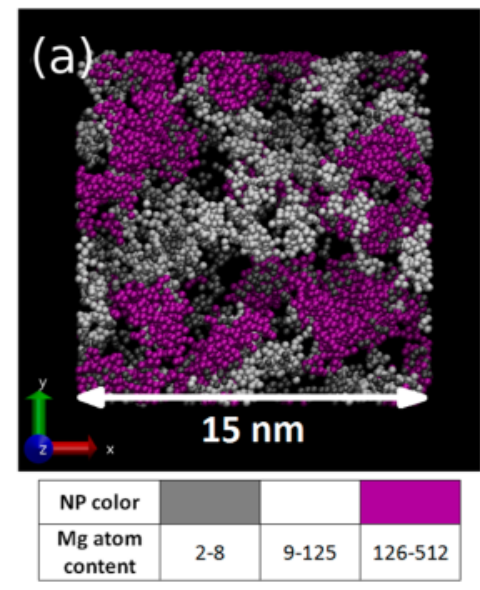

(b)

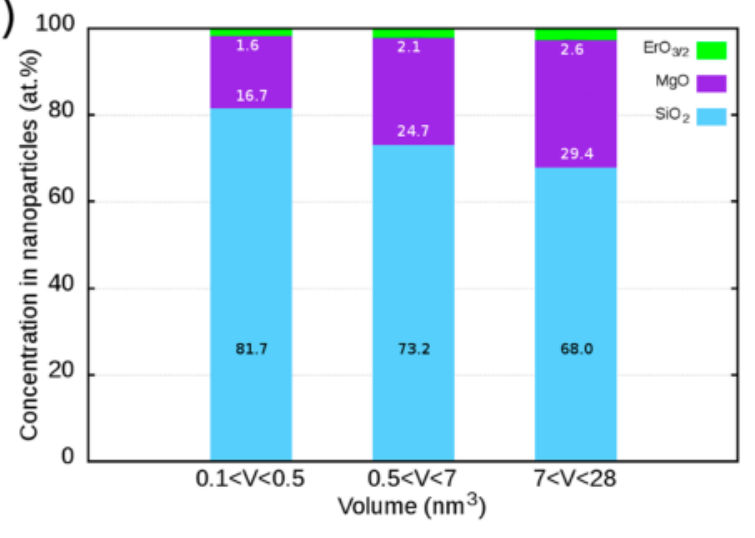

Figure 4. (a) $3 \mathrm{D}$ rendering of the quenched structure of $0.01 \mathrm{ErO}_{3 / 2}-0.10 \mathrm{MgO}-0.89 \mathrm{SiO}_{2}$ glass. Only $\mathrm{Mg}$ atoms are shown, but a color code is applied to discriminate them according to the size of the nanoparticle in which they are located. $\mathrm{Mg}$ atoms separated by less than $0.43 \mathrm{~nm}$ (first minimum of the $\mathrm{Mg}-\mathrm{Mg}$ radial distribution function) are considered to belong to the same DNP. (b) Nanoparticles composition vs their volume ( $\mathrm{MD}$ simulation). The elemental concentrations are indicated in the column bars (top, middle, and bottom values correspond to $\mathrm{ErO}_{3 / 2}, \mathrm{MgO}$, and $\mathrm{SiO}_{2}$, respectively).

measurement on a "big" nanoparticle, not fully contained in the etched tip, indicates a concentration of 38 at. $\% \mathrm{Mg}$ and 11 at. \% P. Although semiquantitative, both techniques show $\mathrm{Mg}$ and $\mathrm{P}$ contents continue increasing for nanoparticles of radii larger than $10 \mathrm{~nm}$. Note that if we consider the $\mathrm{SiO}_{2}-\mathrm{MgO}$ phase diagram, for a $1 \mathrm{~mol} \% \mathrm{MgO}$ content, the expected phase separated particles concentration would lead to $40 \mathrm{MgO}$ $60 \mathrm{SiO}_{2}$ (in mol \%). ${ }^{23}$ Although $\mathrm{GeO}_{2}, \mathrm{P}_{2} \mathrm{O}_{5}$, and $\mathrm{Er}_{2} \mathrm{O}_{3}$ contents are low in our samples, 'large' nanoparticle composition, measured via EDX and APT, still remains close to those expected considering the phase diagram. ${ }^{24}$

The data set in this study demonstrates existence of a first plateau, followed by a second trend in which particle composition changes (Figure 3). Classical nucleation theory (CNT), formulated to explain the nucleation/growth mechanism, is based on nanocrystals clustering, and their growth. Capillary approximation of this model predicts that above the critical radius, the nuclei, and the macroscopic phase have identical crystalline structures and composition. However, several aspects of this model are disproved by experimental evidence. ${ }^{25-30}$ Interestingly, recent theories based on Cahn and Hilliard's approach suggest nanoparticles do not reach final composition at a given radius (critical radius in the frame of the CNT). Instead, their composition varies over a range of diameters before reaching final composition. ${ }^{31-37}$ In these models, particle evolution is divided into three parts: (i) composition of smaller particles remains constant with size; (ii) particle composition starting to change at a given radius (named Rs); (iii) for radius larger than 2-4 Rs, the particle composition is very close to the final composition. Experimental results obtained in alloy confirmed composition variation vs size for particles smaller than $10 \mathrm{~nm}$, but the first plateau was not observed. ${ }^{35-37}$ These models were established for a binary solution heated at a constant temperature. Although our multicomponent glass was heated according to cyclic heat-treatments, we observed typical features related to these models. Our model system does not allow cluster study during the growth phase, but instead captures snapshots of an entire range of clusters at a given time. In steel, cluster composition depends only on the radius and is not time dependent. $^{36,37}$ We therefore infer that the smallest nano- particles correspond to early stages of the phase separation mechanism.

Nanoparticle chemical compositions were also investigated via molecular dynamics simulations. We developed a transferable and adaptive model that describes, for the first time, the separation of large phases in the $\mathrm{MgO}-\mathrm{SiO}_{2}$ binary system. ${ }^{17}$ This model has been extended to $\mathrm{MgO}-\mathrm{SiO}_{2}-\mathrm{Eu}_{2} \mathrm{O}_{3}{ }^{38}$ and, more specifically, applied to the $0.1 \mathrm{MgO}-0.89 \mathrm{SiO}_{2}-$ $0.01 \mathrm{ErO}_{3 / 2}$ system in the present study. All details are given in the Supporting Information. For statistical relevance, the simulated composition contains more $\mathrm{Mg}$ and $\mathrm{Er}$ than the investigated sample. A direct comparison between simulated and experimental results is outside this paper's scope, due to the difficulty of describing such a complex system. Thus, with this model, the simulation box was limited to $15 \mathrm{~nm}$ to reduce computation time, and the maximum mean nanoparticle radius obtained was approximately $1.8 \mathrm{~nm}$. The heating treatment of the $0.1 \mathrm{MgO}-0.89 \mathrm{SiO}_{2}-0.01 \mathrm{ErO}_{3 / 2}$ system did not include quenching rate. $\mathrm{A} 3 \mathrm{D}$ rendering of a nanostructured $0.01 \mathrm{ErO}_{3 / 2}-0.10 \mathrm{MgO}-0.89 \mathrm{SiO}_{2}$ glass, obtained after a quench at $0.01 \mathrm{~K} / \mathrm{ps}$ of a melt structure, is shown in Figure 4a. Although only $\mathrm{Mg}$ atoms are presented, a color code allows visualizing their clustering as nanoparticles of various sizes. $\mathrm{Mg}$ atoms separated by less than $0.43 \mathrm{~nm}$ (1st minimum of the $\mathrm{Mg}-\mathrm{Mg}$ radial distribution function ${ }^{17}$ ) are considered part of the same nanoparticle. These nanoparticles appear amorphous and aspherical. Variation of nanoparticle composition by size is also predicted by the simulation (Figure $4 \mathrm{~b}$ ), with results in strong agreement with the trend observed experimentally. The nanoparticle $\mathrm{SiO}_{2}$ content is large, and the $\mathrm{Mg}$ concentration increases with particle size. Although the APT results revealed Er partitioning within the nanoparticle, the technique was not sensitive enough to quantify small Er content variations. The simulation provides this additional information and predicts an increase of Er concentration with particle size.

$\mathrm{Er}^{3+}$ Environment vs. Nanoparticle Size. As nanoparticle composition changes with size, a question arises regarding evolution of the $\mathrm{Er}^{3+}$ ion immediate environment. In this section, we consider $\mathrm{Er}^{3+}$ ions located inside particles. Study of $\mathrm{Er}^{3+}$ atoms short-range order shows that the close environment of $\mathrm{Er}^{3+}$ is enriched with $\mathrm{O}$ and $\mathrm{Mg}$ ions as first 
Table 1. $\mathrm{Er}^{3+}$ Environment vs Volume of Containing Nanoparticles ${ }^{a}$

\begin{tabular}{|c|c|c|c|c|c|c|c|c|}
\hline \multirow[b]{2}{*}{ nanoparticles volume $V\left(\mathrm{~nm}^{3}\right)$} & \multicolumn{8}{|c|}{$\mathrm{Er}^{3+}$ coordination with } \\
\hline & NNO & $\mathrm{NBO}^{*}$ & $\mathrm{NBO}^{* * *}$ & $\mathrm{BO}^{*}$ & O total & $\mathrm{Si}$ & $\mathrm{Mg}$ & Er \\
\hline $0.1<V<0.5$ & 0.1 & 1.2 & 3.7 & 1.3 & 6.3 & 6.9 & 1.9 & 0.2 \\
\hline $0.5<V<7$ & 0.2 & 0.9 & 4.4 & 1.1 & 6.6 & 6.7 & 3.3 & 0.3 \\
\hline $7<V<28$ & 0.3 & 0.7 & 4.8 & 0.9 & 6.7 & 6.5 & 4.2 & 0.5 \\
\hline
\end{tabular}

${ }^{a} \mathrm{NNO}=$ oxygen with no link to $\mathrm{Si} ; \mathrm{NBO}^{*}=$ non-bridging divalent oxygen; $\mathrm{NBO}^{* *}=$ non-bridging trivalent oxygen; $\mathrm{BO}^{*}=$ bridging trivalent oxygen; $\mathrm{O}$ total corresponds to the sum of all oxygen atoms; $\mathrm{Er}-\mathrm{O}, \mathrm{Er}-\mathrm{Si}, \mathrm{Er}-\mathrm{Mg}$, and $\mathrm{Er}-\mathrm{Er}$ cutoffs are $0.29,0.41,0.46$, and $0.47 \mathrm{~nm}$, respectively).

and second neighbors, respectively, when particle size increases (Table 1). Examination of the various well-defined oxygen binding possibilities within the glass environment provides further insight of $\mathrm{Er}^{3+}$ structural rearrangement. The six possible variables are (i) bridging oxygen (BO), where an $\mathrm{O}$ atom is bound to two silicon atoms, thus fully participating in the $\mathrm{SiO}_{2}$ network; (ii) non-bridging oxygen (NBO), where the oxygen is bound to a single silicon atom; (iii) divalent bridging oxygen $\left(\mathrm{BO}^{*}\right)$, where the $\mathrm{O}$ atom is bound to two silicon atoms and another cation (erbium or magnesium); (iv) divalent non-bridging oxygen $\left(\mathrm{NBO}^{*}\right)$, where the $\mathrm{O}$ atom is bound to a single silicon atom and another cation; (v) trivalent non-bridging oxygen $\left(\mathrm{NBO}^{* *}\right)$, where the $\mathrm{O}$ atom is bound to one silicon and two other cations (erbium and/or magnesium), and (vi) non-network oxygen ( $\mathrm{NNO}$ ), where the $\mathrm{O}$ atom is not bound to any silicon. The cutoffs for $\mathrm{Si}-\mathrm{O}, \mathrm{Mg}-\mathrm{O}$, and Er-O bonds are 2.1, 2.9, and $2.9 \AA$ respectively, which correspond to the first minimum of cation-oxygen radial distribution function. For an ideal $\mathrm{SiO}_{2}$ glass, $100 \%$ of the $\mathrm{O}$ atoms are BO (99.3\% with our numerical simulations).

The high percentage of $\mathrm{Er}^{3+}(2.6 \mathrm{~mol} \%)$ in the largest nanoparticles should favor greater rare-earth ion clustering. However, analysis of neighboring $\mathrm{Er}^{3+}$ atoms shows the opposite. Indeed, a simulation with binary $\mathrm{ErO}_{3 / 2}-\mathrm{SiO}_{2}$ glass containing $2.6 \mathrm{~mol} \% \mathrm{Er}^{3+}$, shows that $65 \%$ of $\mathrm{Er}^{3+}$ ions aggregate. In comparison, in $\mathrm{ErO}_{3 / 2}-\mathrm{MgO}-\mathrm{SiO}_{2}$ nanoparticles containing the same $\mathrm{Er}^{3+}$ concentration, the $\mathrm{Er}^{3+}$ clustering amount drops to $39 \%$. Against all expectations, the clustering effect in nanoparticles is almost halved, something that could be explained by $\mathrm{NBO}^{* *}$ presence in nanoparticles. Indeed, in silica glass, erbium ions tend to aggregate, to share scarce NBO $* *{ }^{39}$ For this reason, when phosphorus is incorporated into silica, there is preferential coordination of $\mathrm{Er}$ with $\mathrm{P}$, as this cation tends to depolymerize the $\mathrm{SiO}_{2}$ network (i.e., creates $\mathrm{NBO}) .^{40}$ To discuss the role of $\mathrm{Mg}$ and $\mathrm{O}$ ions, the complete analysis of the $\mathrm{Er}^{3+}$ environment with nanoparticles size is presented in Table 1 . When introduced into vitreous silica, $\mathrm{Mg}^{2+}$ ions create $\mathrm{BO}^{*}, \mathrm{NBO}^{*}, \mathrm{NBO}^{* *}$, and a few $\mathrm{NNO}$. It can be seen that the larger the nanoparticle, the more $\mathrm{Mg}$ atoms surround $\mathrm{Er}^{3+}$. The $\mathrm{Mg}$ presence brings $\mathrm{NBO}^{* * *}$ (Table 1), giving $\mathrm{Er}^{3+}$ the opportunity to increase oxygen coordination without use of rare-earth aggregation.

\section{DISCUSSION}

The properties of rare-earth elements in glass ceramics materials have been extensively described in literature on rare-earth doped nanocrystals. In particular, these studies demonstrate that these materials' spectroscopic properties are altered by their nanocrystal size. More precisely, these works describe how nanoparticle size influences: phonon frequency cutoff, $^{41}$ interactions between rare-earth ions and defects at the surface of nanocrystals, ${ }^{42}$ the refractive index, ${ }^{43}$ the rare-earth two level-system (of the glassy host) interaction, ${ }^{44}$ and the interaction of lanthanides ions with a new mixed vibrational state, potentially resulting from glass vibrational and nanocrystals phonon modes. ${ }^{45}$ In all these studies, despite nanocrystal size variation, possible nanoparticle composition modification by size remained unexplored. Although conducted on amorphous phase-separated nanoparticles, our experimental results and $\mathrm{MD}$ simulations are unique in revealing a change in rare-earth ions close environment composition based on nanoparticle size, a composition change known to strongly influence material spectroscopic properties. ${ }^{15}$ Therefore, we postulate that the dependence of luminescent properties is associated with composition changes that we show to be nanoparticle size-dependent. Our hypothesis is partially supported by previous work in which larger nanoparticles were obtained by increasing $\mathrm{Mg}$ content, leading to $\mathrm{Er}^{3+}$ emission spectra broadening. ${ }^{46}$ However, classic emission characterization techniques only provide global information regarding a fiber's optical properties, which, in the present study, comprises the sum of all individual $\mathrm{Er}^{3+}$ emission spectra embedded in nanoparticles of a few hundred nanometers in size. Utilizing the super resolution microscopy technique, ${ }^{47}$ for example, potentially would allow exploring luminescence properties at the nanoparticle level. These results highlight that the smallest nanoparticles, although preferred for application in photonics as they reduce light scattering, may not be the best adapted to the nanoengineering of rare earth luminescence properties as their composition is similar to that of the matrix.

Fundamentally, nanoparticle composition modification also could provide new insight into the crystallization processes. We suggest amorphous nanoparticles could be seen as a precursor to crystalline nanoparticles formation, in which the final composition will be determined not by the "bud" size critical radius, as defined by the classical theory, but rather by when nanoparticles reach a size larger than "compositional" critical radius (i.e., when nanoparticle composition becomes congruent with crystalline phase). In addition, the nanoparticle refractive index is expected to be size-dependent and therefore may affect our understanding of light scattering in glasses that contain polydispersed nanoparticles. Finally, these results will help to understand the mechanisms underlying the phase separation, a process broadly used to trigger the nanoparticles formation.

\section{CONCLUSIONS}

This study demonstrates, for the first time, that the chemical composition of amorphous phase-separated nanoparticles produced via phase separation in silicate glasses is nanoparticle size-dependent. $\mathrm{Er}^{3+}$ partitioning in nanoparticles is associated with an increase in $\mathrm{Mg}$ and $\mathrm{P}$ ions content for the smaller nanoparticles, of radii in the $1-10 \mathrm{~nm}$ range. $\mathrm{Er}^{3+}$ ion 
clustering becomes less pronounced in nanoparticles than in glass bulk, due to the beneficial role of elements such as $\mathrm{Mg}$, which we found to be more abundant in larger nanoparticles.

These results contribute important insights regarding fluorescence properties of rare-earth doped amorphous nanoparticles, and directly apply to the field of transparent glass-ceramics material, in which the primary goal is reducing nanoparticle size to improve transparency. This approach may require additional consideration when applied, as our results highlight the trade-off between using small-size nanoparticles and larger nanoparticles. The smaller particles reduce light scattering in glass, while the larger ones could specifically be nanoengineered to optimize the glasses' material luminescence properties.

\section{ASSOCIATED CONTENT}

\section{S Supporting Information}

The Supporting Information is available free of charge on the ACS Publications website at DOI: 10.1021/acs.jpcc.9b08577.

Detailed experimental procedures (sample preparation and atom probe tomography and transmission electron microscopy characterizations), molecular dynamics simulations details, Figure S1, sequence of electron micrographs showing the extraction of a $20-\mu \mathrm{m}$ long Ptcoated lamella followed by tip sharpening for APT or preparation for TEM, and Table S1, parameters of the transferable adaptive interatomic potential (PDF)

\section{AUTHOR INFORMATION}

\section{Corresponding Author}

*(W.B.) E-mail: wilfried.blanc@inphyni.cnrs.fr. Telephone: +33489152839.

\section{ORCID}

Wilfried Blanc: 0000-0002-7512-3916

\section{Present Address}

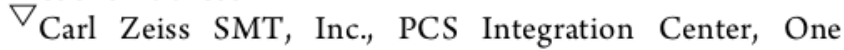
Corporation Way 1, Peabody, MA 01960

\section{Notes}

The authors declare no competing financial interest.

\section{ACKNOWLEDGMENTS}

The authors acknowledge S. Trzesien and M. Ude (INPHYNI, Nice, France) for the fabrication of the samples. This work was supported by ANR Projects Nice-DREAM (ANR-14-CE070016-03) and NanoSlim (ANR-17-CE08-0002). This research used computational facilities of the CCIPL (Centre de Calcul Intensif des Pays de la Loire, France). Imaging was performed on the Bordeaux Imaging Center, member of the FranceBioImaging national infrastructure (ANR-10-INBS-04). The authors thank Laura Frost for her careful reading and editing of this manuscript.

\section{REFERENCES}

(1) From glass to crystal: Nucleation, growth and phase separation: from research to applications; Neuville, D. R., Cornier, L., Caurant, D., Montagne, L., Eds.; EDP Sciences: Les Ulis, France, 2017.

(2) De Yoreo, J. J.; Gilbert, P. U.; Sommerdijk, N. A.; Penn, R. L.; Whitelam, S.; Joester, D.; Zhang, H.; Rimer, J. D.; Navrotsky, A.; Banfield, J. F.; Wallace, A. F.; et al. Crystallization by particle attachment in synthetic, biogenic, and geologic environments. Science 2015, 349, aaa6760.
(3) Di Genova, D.; Kolzenburg, S.; Wiesmaier, S.; Dallanave, E.; Neuville, D. R.; Hess, K. U.; Dingwell, D. B. A compositional tipping point governing the mobilization and eruption style of rhyolitic magma. Nature 2017, 552, 235-238.

(4) Auzel, F.; Pecile, D.; Morin, D. Rare earth doped vitroceramics: New, efficient, blue and green emitting materials for infrared upconversion. J. Electrochem. Soc. 1975, 122, 101-107.

(5) Gonçalves, M. C.; Santos, L. F.; Almeida, R. M. Rare-earthdoped transparent glass ceramics. C. R. Chim. 2002, 5, 845-854.

(6) Ferrari, M.; Righini, G. C. Glass-ceramic materials for guidedwave optics. Int. J. Appl. Glass Sci. 2015, 6, 240-248.

(7) Blanc, W.; Dussardier, B. Formation and applications of nanoparticles in silica optical fibers. J. Opt. 2016, 45, 247-254.

(8) Kasik, I.; Peterka, P.; Mrazek, J.; Honzatko, P. Silica optical fibers doped with nanoparticles for fiber lasers and broadb and sources. Curr. Nanosci. 2016, 12, 277-290.

(9) Tick, P. Are low-loss glass-ceramic optical waveguides possible? Opt. Lett. 1998, 23, 1904-1905.

(10) Shepilov, M. P.; Dymshits, O. S.; Zhilin, A. A. Light scattering in glass-ceramics: revision of the concept. J. Opt. Soc. Am. B 2018, 35, $1717-1724$.

(11) Borrelli, N.; Mitchell, A.; Smith, C. Relationship between morphology and transparency in glass-ceramic materials. J. Opt. Soc. Am. B 2018, 35, 1725-1732.

(12) Vermillac, M.; Lupi, J. F.; Peters, F.; Cabie, M.; Vennegues, P.; Kucera, C.; Neisius, T.; Ballato, J.; Blanc, W. Fiber-draw-induced elongation and break-up of particles inside the core of a silica-based optical fiber. J. Am. Ceram. Soc. 2017, 100, 1814-1819.

(13) Jehannin, M.; Rao, A.; Cölfen, H. New horizons of nonclassical crystallization. J. Am. Chem. Soc. 2019, 141, 10120-10136.

(14) Zhou, J.; Yang, Y.; Yang, Y.; Kim, D. S.; Yuan, A.; Tian, X.; Ophus, C.; Sun, F.; Schmid, A. K.; Nathanson, M.; Heinz, H. Observing crystal nucleation in four dimensions using atomic electron tomography. Nature 2019, 570, 500-503.

(15) Spectroscopic properties of rare earths in optical materials; Liu, G., Jacquier, B., Eds.; Springer-Verlag: Berlin and Heidelberg, Germany, 2006.

(16) Blanc, W.; Guillermier, C.; Dussardier, B. Composition of nanoparticles in optical fibers by Secondary Ion Mass Spectrometry. Opt. Mater. Express 2012, 2, 1504-1510.

(17) Bidault, X.; Chaussedent, S.; Blanc, W. A simple transferable adaptive potential to study phase separation in large-scale $\mathrm{xMgO}-(1$ x) $\mathrm{SiO}_{2}$ binary glasses. J. Chem. Phys. 2015, 143, 154501.

(18) Hellman, O. C.; Vandenbroucke, J. A.; Rüsing, J.; Isheim, D.; Seidman, D. N. Analysis of three-dimensional atom-probe data by the proximity histogram. Microsc. Microanal. 2000, 6, 437-444.

(19) Local Electrode Atom Probe Tomography: A User's Guide; Larson, D., Prosa, T., Ulfig, R., Geiser, B., Kelly, T., Eds.; Springer-Verlag: New York, 2013.

(20) Sha, G.; Cerezo, A. Field ion microscopy and 3-D atom probe analysis of $\mathrm{Al}_{3} \mathrm{Zr}$ particles in $7050 \mathrm{Al}$ alloy. Ultramicroscopy 2005, 102, 151-159.

(21) Marquis, E.; Vurpillot, F. Chromatic aberrations in the field evaporation behavior of small precipitates. Microsc. Microanal. 2008, $14,561-570$.

(22) Krug, M. E.; Werber, A.; Dunand, D. C.; Seidman, D. N. Coreshell nanoscale precipitates in $\mathrm{Al}-0.06$ at.\% Sc microalloyed with $\mathrm{Tb}$, Ho, Tm or Lu. Acta Mater. 2010, 58, 134-145.

(23) Bowen, N.; Andersen, O. The binary system $\mathrm{SiO}_{2}-\mathrm{MgO}$. Am. J. Sci. 1914, s4-37, 487-500.

(24) Kim, S. S.; Sanders, T. H. Thermodynamic modeling of the miscibility gaps and the metastable liquidi in the $\mathrm{MgO}_{-} \mathrm{SiO}_{2}, \mathrm{CaO}$ $\mathrm{SiO}_{2}$ and $\mathrm{SrO}-\mathrm{SiO}_{2}$ systems. J. Am. Ceram. Soc. 1999, 82, 1901-1907.

(25) Sen, S.; Mukerji, T. A generalized classical nucleation theory for rough interfaces: application in the analysis of homogeneous nucleation in silicate liquids. J. Non-Cryst. Solids 1999, 246, 229-239.

(26) Pouget, E. M.; Bomans, P. H.; Goos, J. A.; Frederik, P. M.; Sommerdijk, N. A.; et al. The initial stages of template-controlled 
$\mathrm{CaCO}_{3}$ formation revealed by cryo-TEM. Science 2009, 323, 14551458.

(27) Chung, S. Y.; Kim, Y. M.; Kim, J. G.; Kim, Y. J. Multiphase transformation and Ostwald's rule of stages during crystallization of a metal phosphate. Nat. Phys. 2009, 5, 68-73.

(28) Dey, A.; Bomans, P. H.; Müller, F. A.; Will, J.; Frederik, P. M.; de With, G.; Sommerdijk, N. A. The role of prenucleation clusters in surface-induced calcium phosphate crystallization. Nat. Mater. 2010, 9, 1010-1014.

(29) Baumgartner, J.; Dey, A.; Bomans, P. H.; Le Coadou, C.; Fratzl, P.; Sommerdijk, N. A.; Faivre, D. Nucleation and growth of magnetite from solution. Nat. Mater. 2013, 12, 310-314.

(30) Tan, P.; Xu, N.; Xu, L. Visualizing kinetic pathways of homogeneous nucleation in colloidal crystallization. Nat. Phys. 2014, $10,73-79$.

(31) Cahn, J. W.; Hilliard, J. E. Free energy of a nonuniform system. III. Nucleation in a 2-component incompressible fluid. J. Chem. Phys. $1959,31,688-699$.

(32) Schmelzer, J. W.; Schmelzer, J., Jr; Gutzow, I. S. Reconciling Gibbs and van der Waals: A new approach to nucleation theory. J. Chem. Phys. 2000, 112, 3820-3831.

(33) Schmelzer, J. W.; Abyzov, A. S.; Möller, J. Nucleation versus spinodal decomposition in phase formation processes in multicomponent solutions. J. Chem. Phys. 2004, 121, 6900-6917.

(34) Bonvalet, M.; Philippe, T.; Sauvage, X.; Blavette, D. The influence of size on the composition of nano-precipitates in coherent precipitation. Philos. Mag. 2014, 94, 2956-2966.

(35) Tatchev, D.; Goerigk, G.; Valova, E.; Dille, J.; Kranold, R.; Armyanov, S.; Delplancke, J. L. Investigation of the primary crystallization of $\mathrm{Ni}-17$ at.\% P alloy by ASAXS. J. Appl. Crystallogr. 2005, 38, 787-794.

(36) Mulholland, M. D.; Seidman, D. N. Nanoscale co-precipitation and mechanical properties of a high-strength low-carbon steel. Acta Mater. 2011, 59, 1881-1897.

(37) Chbihi, A.; Sauvage, X.; Blavette, D. Atomic scale investigation of $\mathrm{Cr}$ precipitation in copper. Acta Mater. 2012, 60, 4575-4585.

(38) Turlier, J.; Chaussedent, S.; Bidault, X.; Gaumer, N. B.; Guichaoua, D.; Raso, P.; Fneich, H.; Mehdi, A.; Neuville, D. R.; Vermillac, M.; Blanc, W. Molecular dynamics study of rare-earth doped $\mathrm{Mg}$-silicate nanoparticles in vitreous silica: from the preform to the fiber. Fiber Lasers and Glass Photonics: Materials through Applications 2018, 103.

(39) Murata, T.; Moriyama, Y.; Morinaga, K. Relationship between the local structure and spontaneous emission probability of $\mathrm{Er}^{3+}$ in silicate, borate, and phosphate glasses. Sci. Technol. Adv. Mater. 2000, 1, 139-145.

(40) Saitoh, A.; Matsuishi, S.; Se-Weon, C.; Nishii, J.; Oto, M.; Hirano, M.; Hosono, H. Elucidation of codoping effects on the solubility enhancement of $\mathrm{Er}^{3+}$ in $\mathrm{SiO}_{2}$ glass: Striking difference between $\mathrm{Al}$ and $\mathrm{P}$ codoping. J. Phys. Chem. B 2006, 110, 7617-7620. (41) Chen, X.; Zhuang, H.; Liu, G.; Li, S.; Niedbala, R. Confinement on energy transfer between luminescent centers in nanocrystals. $J$. Appl. Phys. 2003, 94, 5559-5565.

(42) Gargas, D. J.; Chan, E. M.; Ostrowski, A. D.; Aloni, S.; Altoe, M. V. P.; Barnard, E. S.; Sanii, B.; Urban, J. J.; Milliron, D. J.; Cohen, B. E.; Schuck, P. J. Engineering bright sub-10-nm upconverting nanocrystals for single-molecule imaging. Nat. Nanotechnol. 2014, 9, $300-305$.

(43) LeBihan, V.; Pillonnet, A.; Amans, D.; Ledoux, G.; Marty, O.; Dujardin, C. Critical dimension where the macroscopic definition of refractive index can be applied at a nanometric scale. Phys. Rev. B: Condens. Matter Mater. Phys. 2008, 78, 113405.

(44) Meltzer, R.; Yen, W. M.; Zheng, H.; Feofilov, S. P.; Dejneka, M. J.; Tissue, B. M.; Yuan, H. B. Evidence for long-range interactions between rare-earth impurity ions in nanocrystals embedded in amorphous matrices with the two-level systems of the matrix. Phys. Rev. B: Condens. Matter Mater. Phys. 2001, 64, 100201.

(45) Meltzer, R.; Yen, W.; Zheng, H.; Feofilov, S.; Dejneka, M. Relaxation between closely spaced electronic levels of rare-earth ions doped in nanocrystals embedded in glass. Phys. Rev. B: Condens. Matter Mater. Phys. 2002, 66, 224202.

(46) Blanc, W.; Mauroy, V.; Nguyen, L.; Shivakiran Bhaktha, B. N.; Sebbah, P.; Pal, B. P.; Dussardier, B. Fabrication of rare earth-doped transparent glass ceramic optical fibers by modified chemical vapor deposition. J. Am. Ceram. Soc. 2011, 94, 2315-2318.

(47) Kolesov, R.; Reuter, R.; Xia, K.; Stöhr, R.; Zappe, A.; Wrachtrup, J. Super-resolution upconversion microscopy of praseodymium-doped yttrium aluminum garnet nanoparticles. Phys. Rev. B: Condens. Matter Mater. Phys. 2011, 84, 153413. 